\title{
Home range, activity cycle and natal den usage of a female Sunda pangolin Manis javanica (Mammalia: Pholidota) in Singapore
}

\author{
Norman T. L. Lim*, Peter K. L. Ng \\ Department of Biological Sciences, National University of Singapore, 14 Science Drive 4, Singapore 117543
}

\begin{abstract}
Here we present the first field report on the ecology of a single female Sunda pangolin and her young in their natural habitat on an offshore island of Singapore. Observations of this event were made possible by the use of radio-telemetry and infrared-triggered camera traps. Only one offspring was recorded from this birth event and the period of maternal care was approximately 3 to $4 \mathrm{mo}$. A total of 3 natal dens were used throughout the monitoring period, and hollows of large trees ( $>50 \mathrm{~cm}$ diameter at breast height, DBH) were associated with all dens. The 100 and $95 \%$ home range estimated by minimum convex polygons is 6.97 and $5.63 \mathrm{ha}$, respectively. The daily active period of the pangolin was $127 \pm 13.1 \mathrm{~min}$, and peak activity levels were between 03:00 and 06:00 h. The findings of this report are discussed in relation to the conservation challenges confronting this species.
\end{abstract}

KEY WORDS: Manis javanica $\cdot$ Pholidota $\cdot$ Pangolin $\cdot$ Home range $\cdot$ Activity $\cdot$ Den use

Resale or republication not permitted without written consent of the publisher

\section{INTRODUCTION}

Pangolins (Manis spp.) are members of the only family (Manidae) in the order Pholidota and there are only 8 extant species in the world. With the exception of the Palawan pangolin Manis culionenis, which was recently proposed to be distinct from M. javanica (see Gaubert \& Antunes 2005), the Asiatic pangolins (i.e. M. crassicaudata, M. javanica and M. pentadactyla) are classified as 'Lower Risk: near threatened' by the IUCN (2006) and in Appendix II of the Convention on International Trade in Endangered Species of Wild Fauna and Flora (CITES) (Inskipp \& Gillett 2005). Pangolins are largely nocturnal and have adapted to a highly specialized diet of ants and termites (Lekagul \& McNeely 1988). The adaptations include a conical-shaped head, no teeth, a long sticky tongue to lick up the ants or termites, and powerful long claws on its legs for digging and breaking apart ant nests or termite mounds (Payne \& Francis 1998). Their scales, which are composed of keratin, offer excellent protection not only against potential predators, but also from the bites and stings of their ant and termite prey (Payne \& Francis 1998).

The Sunda pangolin Manis javanica is one of the 4 species of Asiatic pangolins and is found in most parts of the southeast Asian region. Despite its relatively wide distribution, there is no detailed study on population levels, ecology and life history of this species. Most of the existing literature on pangolin ecology deals with the cape pangolin $M$. temminckii (see Heath \& Coulson 1997a,b, 1998), Chinese pangolin M. pentadactyla (see Shi 1985, Heath \& Vanderlip 1988, Wu et al. 2003) and tree pangolin M. tricuspis (see Pagés 1975), all of which inhabit different latitudes and habitats, and thus probably have different ecological niches from M. javanica. Much of what is now known about $M$. javanica is anecdotal. Pangolins are believed to give birth to a single offspring each time, although twins have been reported (e.g. Payne \& Francis 1998). However, there are no actual records on the number of births per year, the gestation period or the duration of maternal care for M. javanica (Payne \& Francis 1998). In addition, Wilson (1994) reported that pangolins do 
not survive well in captivity and can suffer $71 \%$ mortality in the first year of captivity. This was also supported by the longevity records kept by the Zoological Society of London, which showed that 10 out of 11 pangolins did not survive the first year (Menzies 1962). Therefore, it is important to carry out field studies to discover more about their breeding ecology and requirements.

In 2005, I (N.T.L.L.) began capturing and radiotracking Manis javanica on an island used primarily by the military for recruit training. The natural vegetation on the island, although largely secondary, has seen relatively low human impact. Images obtained by an infrared-triggered camera trap showed one of the tagged individuals to have one offspring. Here we report on the home range, activity cycles and den usage by this particular female pangolin.
Chou et al. 2006); some Hevea brasiliensis and tropical fruit trees (e.g. Artocarpus heterophyllus, Durio zibethinus, Nephelium lappaceum) are also found in abandoned garden plots within this regenerated forest type (H. T. W. Tan, pers. comm.).

Capture and radiotracking. N.T.L.L. detected pangolins by carefully listening for signs of their activity while walking or cycling with minimal noise along roads and dirt trails after sunset. The sounds of pangolin activity include rustling of leaf litter while the animal moves on the forest floor, and the digging sounds when it makes when excavating an ant nest or termite mound. Pangolins were observed to be very sensitive, and they will either promptly flee or freeze in their tracks when they detect human presence in their immediate vicinity (N. T. L. Lim pers. obs.). Pangolins were then caught by hand. Radio transmitters (AI-2F; $216 \mathrm{MHz}$ band; Holohil Systems), weighing $21 \mathrm{~g}$

\section{MATERIALS AND METHODS}

Study site. The study was conducted on Pulau Tekong $\left(1^{\circ} 24^{\prime} \mathrm{N}, 104^{\circ} 02^{\prime} \mathrm{E}\right)$, an island off the northeastern shore of Singapore (Fig. 1). The climate is characterized by high relative humidity (daily mean: $84.3 \%$ ), temperature (minimum: 23 to $26^{\circ} \mathrm{C}_{i}$ maximum: 31 to $34^{\circ} \mathrm{C}$ ) and rainfall (annual rainfall approximately $2344 \mathrm{~mm}$ ) (Meteorological Services Singapore; www.nea.gov. sg/metsin/). Pulau Tekong has 2350 ha of land and was formerly inhabited by villagers until it was requisitioned as a military training area in 1985 . The 3 main types of vegetation on Pulau Tekong are the mangrove along the northern shore (about 36\%), herbaceous vegetation on the reclaimed southern portion (about $25 \%$ ) and low secondary forest or adinandra belukar (about 16\%). Patches of Elaeis guineensis and Hevea brasiliensis monoculture (about $7.5 \%$ ) are also present, in addition to some built-up areas in the southwestern parts. The herbaceous vegetation includes Imperata cylindrica, Panicum maximum, Pennisetum purpureum, Urochloa mutica and some leguminous trees such as Acacia auriculiformis (Chou et al. 2006). The adinandra belukar forest which occupies most of the central parts of Pulau Tekong is dominated by Adinandra dumosa and Rhodamnia cinerea (see

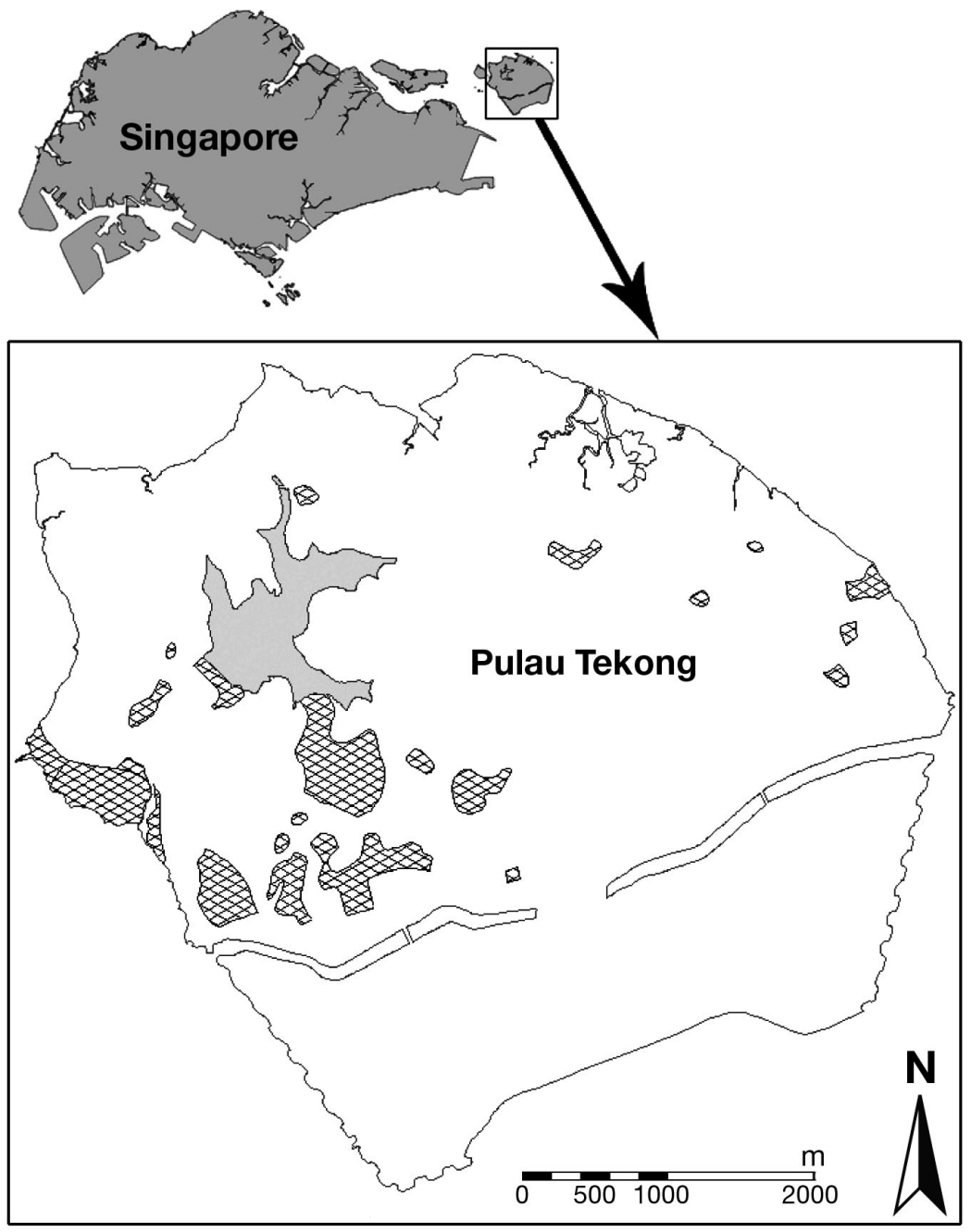

Fig. 1. Island of Singapore showing the location of Pulau Tekong. The grey-shaded area is the only reservoir on the island, and the hatched areas are built up. The remainder of the island is covered with vegetation 
$(0.34 \%$ of the female pangolin body mass) with an average battery lifespan of 12 mo, were fitted onto selected scales on the tail with screws and bolts (Richer et al. 1997). The profile of the transmitter was also streamlined using epoxy putty, to reduce the chances of the transmitter being caught on the dense undergrowth vegetation. Signals from tagged subjects were located with a portable telemetry receiver (R-1000; Communications Specialist) and a directional $\mathrm{H}$ antenna (RA-2A; Telonics). Visual confirmation of subjects was performed during logging of positional data (i.e. triangulation was not performed) and the locations were then recorded using a GPS (GPS 60CS; Garmin International) attached to an active external antenna (Gilsson Technologies); the accuracy of the recorded locations was $\leq 15 \mathrm{~m}$.

Home range. The home range was calculated by minimum convex polygons (MCP; Mohr 1947), using Ranges 7 software (South et al. 2005); 100 and 95\% MCP were computed because these estimates provide good comparison for future home-range studies. The comparison of other methods is complicated by different software packages that use differing algorithms for their computing, and thus produce different results for the same datasets (Lawson \& Rodgers 1997). Since radiotracking was not feasible (see 'Observations'), habitat utilization cannot be estimated from the limited fixes.

Camera trapping and activity patterns. Infraredtriggered camera traps were assembled using a passive infrared sensor (LE Controller Board; PixController) and an Olympus C-120 digital camera. In addition to the 4 ' $\mathrm{AA}$ '-sized batteries in the digital camera, modifications were made to allow for an auxiliary power source of 4 ' $\mathrm{C}$ '-sized batteries. The setup was housed in a weatherproof case (Pelican 1020, Pelican Products). All cameras were operational $24 \mathrm{~h}$ a day and the interval between successive images was set to $10 \mathrm{~s}$ to reduce the number of shots within a short period of time and still obtain a precise timing of the exit/entry.

The term 'den' is herein defined as any site or structure used by a pangolin for extended periods of sleeping or resting. In this instance, the term includes the natal den which is used by the female pangolin for the birth and initial rearing of young. Upon locating a den used by the tagged pangolin, a camera setup was then secured onto a nearby tree trunk, with the lens facing the entrance or exit of the den. All images obtained have day and time information imprinted by the digital camera so that the activity periods could be determined by analyzing the timings of the events (i.e. from exit till re-entry). Incomplete photo records (i.e. when either the exit or the re-entry was absent) were excluded from analysis.

Den description. When a den was identified, its various characteristics were recorded. These include a description of the den and its opening(s), the diameter at breast height $(\mathrm{DBH})$ of the tree associated with the den, the diameter of the opening and also the number of days the den was used by the female Manis javanica (codenamed MJ6) throughout the period.

\section{OBSERVATIONS}

The female Manis javanica (MJ6) captured on 1 September 2005 had a body mass of $6.1 \mathrm{~kg}$, a head-body length of $43 \mathrm{~cm}$ and a tail length of $43 \mathrm{~cm}$. After the radio transmitter had been successfully attached, the individual was released at the site of capture. After allowing MJ6 to acclimatize to the transmitter for a week (White \& Garrot 1990), we performed radiotracking in a bid to locate the dens utilized. On 7 September, MJ6 was seen sleeping alone in a clump of tall grasses. On 8 September, based on the radio-transmitter signals, MJ6 was found to be in an underground den with only one opening. An infrared-triggered camera trap was then set up facing the entrance. Subsequently, activity was detected on the camera trap on all nights (except 8, 9, 13 and 17 September) until the camera trap was knocked out of position on the night of 18 September. There was no access to the study site from 12 to 30 September due to military training constraints. After repositioning the camera trap again on 1 October, MJ6 was recorded on the same night with a much smaller pangolin departing the den for another. This was the first record of the young of MJ6. Based on the image taken on 1 October, the total length of the young pangolin was estimated to be around $80 \%$ of MJ6's tail length, i.e. around 30 to $35 \mathrm{~cm}$.

When radiotracking $\mathrm{MJ} 6$, it was observed that the animal was particularly wary of extraordinary noise and movement, and often headed straight back to its burrow upon detection of our presence. As a result, radiotracking was no longer carried out during the animal's active period, for fear that she would abandon her young. Instead, only non-invasive monitoring was conducted by placing infrared-triggered camera traps at the den entrances and radiotracking during the day to ascertain possible usage of new dens. On 3 November, the antenna of the transmitter was found to have been severed (Fig. 2), thus drastically reducing the effective range of the transmitter. For fear that MJ6 might abandon her young if she experienced distress, MJ6 was not re-captured to replace the faulty transmitter.

From 12 December onwards, there was no record of MJ6 or her young from camera traps positioned at all known dens. On 15 December, MJ6 was found sleeping in a tree cavity $12 \mathrm{~m}$ above ground (only part of the tail was seen), with no visual confirmation of the pres- 


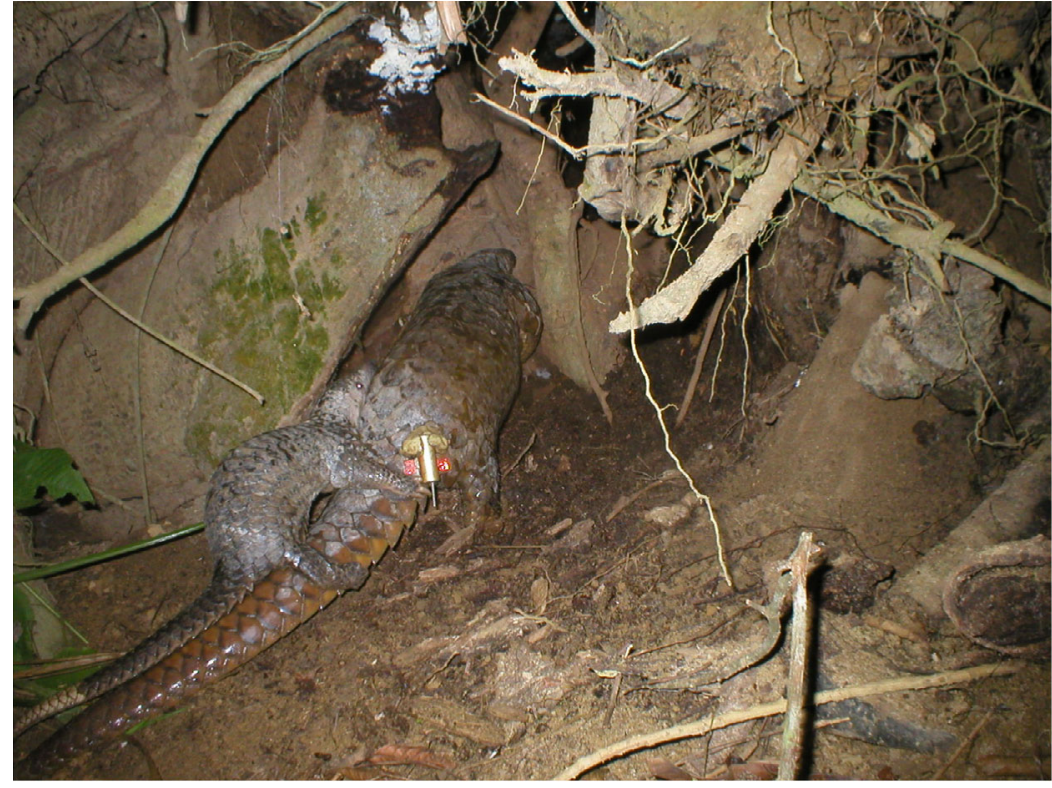

Fig. 2. Manis javanica. Image of MJ6 and her young, taken on 3 November 2005 by infrared-triggered camera traps positioned facing the den entrance. Note that the young is slightly longer than the tail length of MJ6 (1 mo after it was first recorded), and note also the severed antenna of the radio transmitter in October, 27 in November and 55 in the 12 days of December. These events were mainly recorded when the young pangolin was moving around the entrance of the natal dens. Throughout the duration of the camera trapping, there were only 5 occasions when both MJ6 and her young exited the den for foraging trips together (i.e. camera trap recorded exit and entry on same day; excluding relocation to other dens). One of these occurred on 15 November and the others were recorded only in December; 3 of these occasions took place during daylight hours in December. The mean duration of activity with her young was $165.8 \pm 43.5 \mathrm{~min}$ (mean $\left.\pm \mathrm{SE}_{;} \mathrm{n}=5\right)$. Both observations indicate the increase in activity and independence of the young pangolin towards the end of the monitoring period.

\section{Den usage}

ence/absence of her young. On 5 January 2006, MJ6 was first seen foraging without her young (but again there was no opportunity to replace the faulty transmitter). Finally, no signal from MJ6's faulty transmitter was picked up until 21 May, where the shed transmitter was found on the forest floor (Fig. 3 shows a summary of significant events).

\section{RESULTS}

\section{Activity}

Throughout the entire period of camera trapping at den entrances, there were $30 \mathrm{~d}$ on which both entry and exit were successfully recorded by the devices. Based on the timings of the images, the activity pattern throughout the day was compiled (Fig. 4). While peak activity levels were from 03:00 to 06:00 h, there was some activity during the daytime (i.e. 08:00 to 18:00 h), and this diurnal activity was only recorded in the month of December. The daily active period for MJ6 was $127 \pm 13.1$ min (mean $\pm \mathrm{SE}_{;} \mathrm{n}=30$ ).

Since the first record on 1 October, the number of photographs triggered by the young pangolin was 5
Throughout the entire period, MJ6 was found to be utilizing a total of 3 dens (Figs. 5 to 7 ) and their locations are shown in Fig. 8. The characteristics and the duration of usage of the dens are shown in Table 1. The

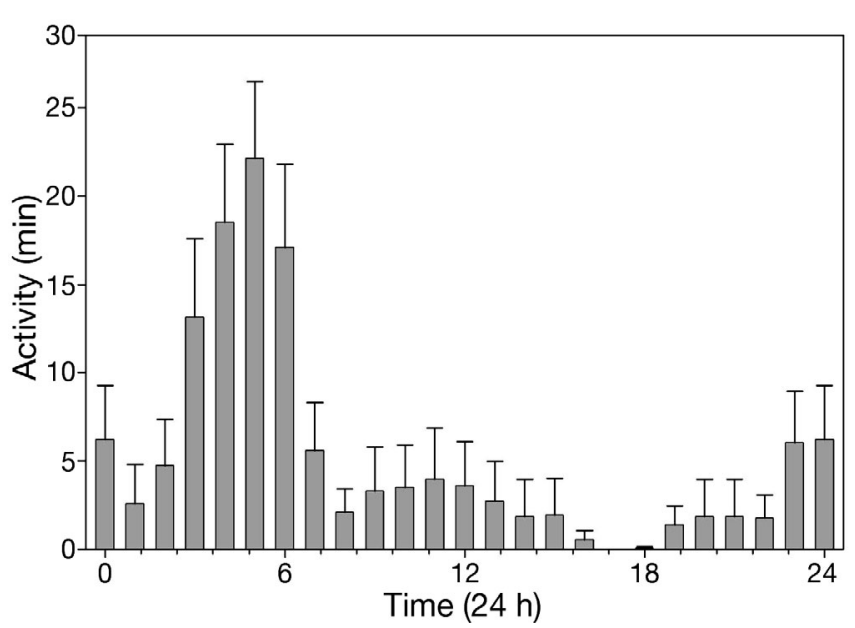

Fig. 4. Manis javanica. Activity pattern of female MJ6 (mean \pm $\mathrm{SE})$, based on $30 \mathrm{~d}$ of camera-trapping data from 8 September to 12 December 2005

$\begin{array}{lllcll}\text { Capture First usage of den } & \text { Young sighted } & \text { Antenna broke off } & \text { End of den usage } & \text { MJ6 first seen without young Shed transmitter found } \\ 1 \text { Sep } 2005 \text { 8 Sep } & \text { 1 Oct } & \text { 3 Nov } & \text { 12 Dec } & \text { 5 Jan 2006 May }\end{array}$

Fig. 3. Manis javanica. Timeline of events for female Sunda pangolin MJ6 and her young 


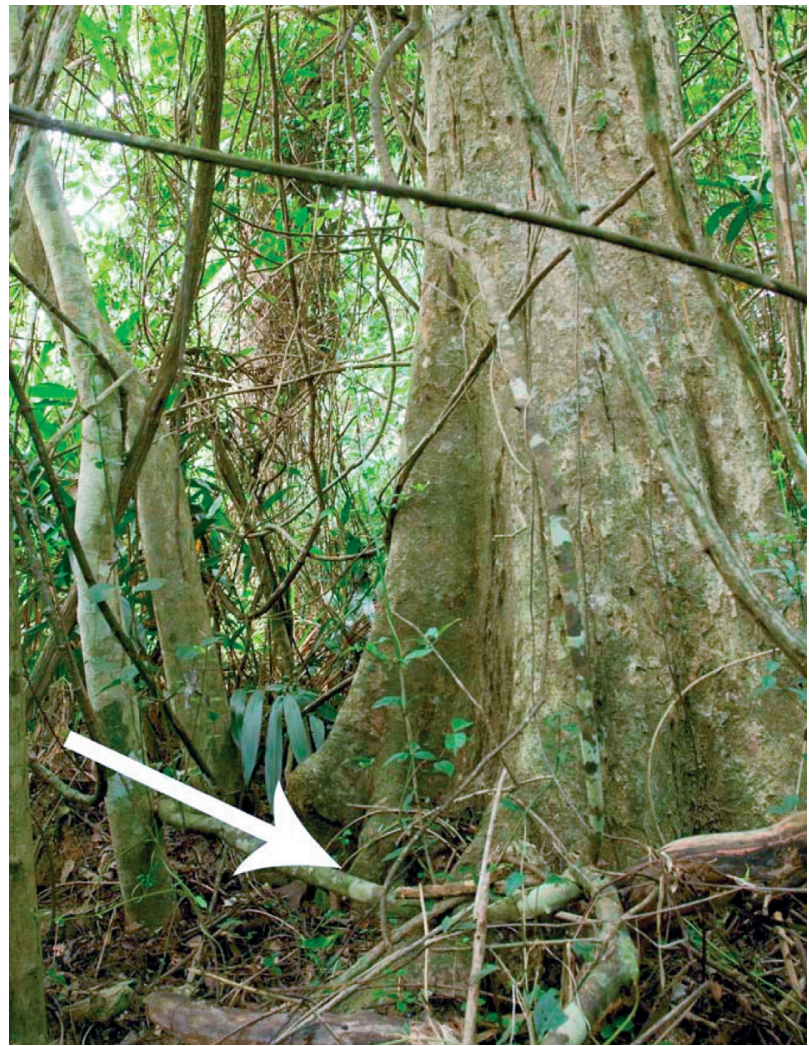

Fig. 5. Manis javanica. Den A and its entrance (arrow)

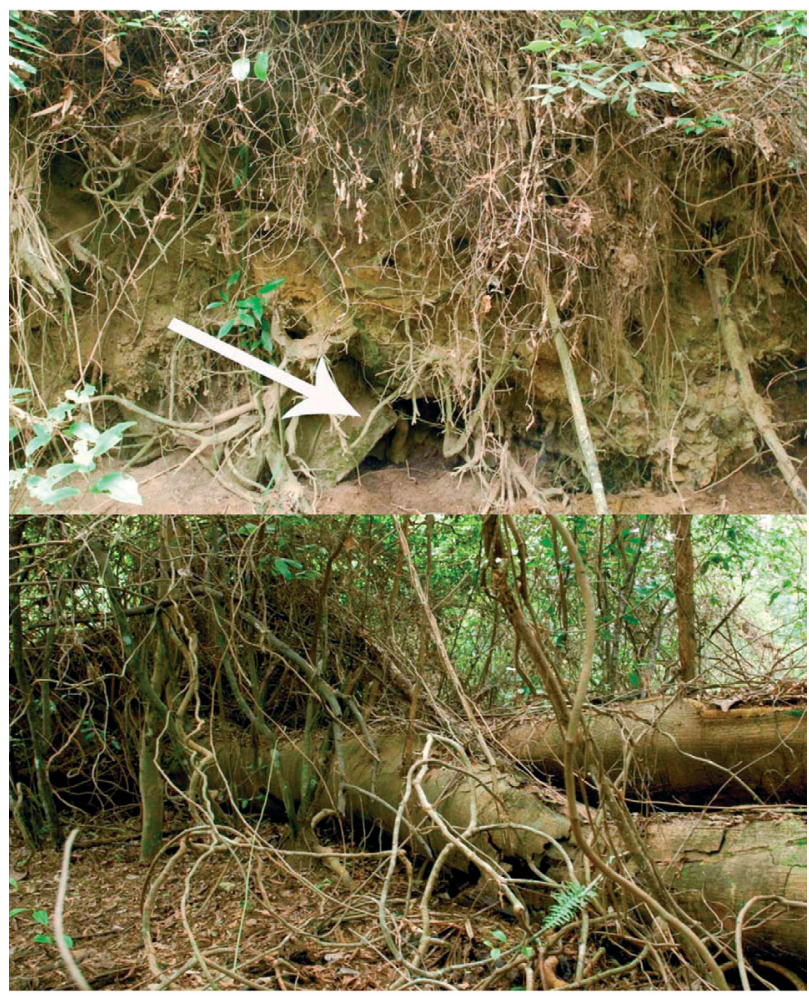

Fig. 6. Manis javanica. Den B and its entrance (top), and fallen tree of Den B (bottom)

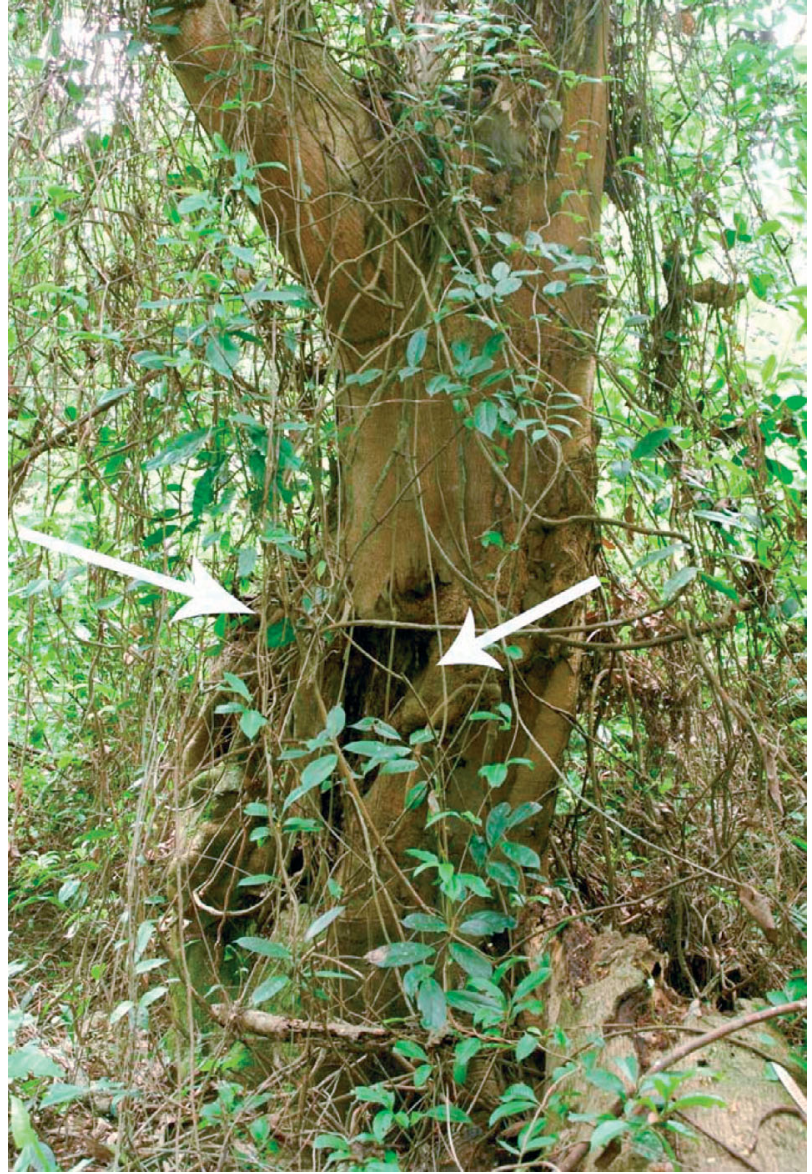

Fig. 7. Manis javanica. Den C and its 2 entrances (arrows)

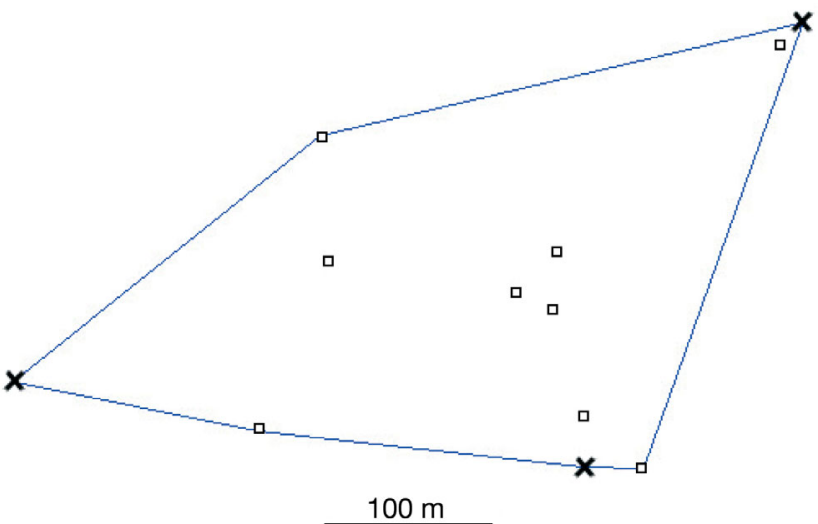

Fig. 8. Manis javanica. Location of the 3 natal dens used by female MJ6 (cross) and positional points from radiotracking (open square)

dens were used consecutively for a mean period of 9.3 $\pm 2.7 \mathrm{~d}$ (mean $\pm \mathrm{SE}_{\mathrm{i}} \mathrm{n}=7$ ) before the animals moved to another den. While Dens A and B were revisited by the pangolins after moving to another den, Den C was only utilized once (for 24 consecutive d). All 3 dens were associated with hollows of large trees $(>50 \mathrm{~cm} \mathrm{DBH})$ 
Table 1. Manis javanica. Description, measurements and duration of usage of the 3 dens used by female MJ6 from September to December 2005. The number of consecutive days of den usage is in parentheses. DBH: diameter at breast height

\begin{tabular}{|llccc|}
\hline Den & \multicolumn{1}{c}{ Description } & $\begin{array}{c}\text { DBH of } \\
\text { tree }(\mathrm{cm})\end{array}$ & $\begin{array}{c}\text { Entrance } \\
\text { diameter }(\mathrm{cm})\end{array}$ & Den usage \\
\hline $\mathrm{A} \quad$ & $\begin{array}{l}\text { Underground burrow leading } \\
\text { to tree hollow of dead tree } \\
\text { (standing); } 1 \text { entrance }\end{array}$ & 95 & 15 & $16 \mathrm{~d}(9+2+5)$ \\
$\mathrm{B} \quad \begin{array}{l}\text { Dead tree (fallen), tree hollow; } \\
\text { entrance at base of tree }\end{array}$ & 54 & 19 & $25 \mathrm{~d}(10+9+6)$ \\
$\mathrm{C} \quad \begin{array}{l}\text { Live tree (standing), tree } \\
\text { hollow; 2 entrances; entrances } \\
1.3 \mathrm{~m} \text { above ground }\end{array}$ & 104 & (1) 24 & $24 \mathrm{~d}(24)$ \\
\hline
\end{tabular}

and offered good shelter from the elements. Two of the dens had only one entrance while the third had 2 entrances leading to the same tree hollow.

\section{Home range}

In addition to the 3 den locations, the limited radiotracking yielded 9 other fixes where MJ6 was seen foraging or resting (Fig. 8). Most of the 9 fixes obtained were within the area enclosed by the 3 dens, suggesting that the dens were at or near the periphery of MJ6's home range. The 100 and 95\% MCP home range is 6.97 and 5.63 ha, respectively.

\section{DISCUSSION}

This is the first detailed report of the activity cycle, den usage and home range of a female Manis javanica during its reproductive stages, made possible by radiotelemetry and the use of non-intrusive infrared-triggered camera traps. Even though this report relies on data from only one individual, we believe that because of the elusive nature of the pangolins and the rare opportunity to radio-tag a female Manis javanica during its reproductive stages, the information collected will contribute significantly towards our knowledge of the life history and ecology of the Sunda pangolin.

By comparing the body measurements of MJ6 to those of similar-sized female pangolins (Table 2), it is most likely that MJ6 was pregnant at the time of capture, thus explaining the big difference in body mass observed between this individual and other females of comparable sizes. While there were no direct observations for the birth of the young pangolin, it is speculated that the birth took place some time between 8 and 17 September 2005. This is because it is highly probable that pangolins will take refuge in a safe location (e.g. tree hollow; Den A), as opposed to a clump of tall grasses (as, for example, on $7 \mathrm{Sep}$ tember), when giving birth and providing maternal care for their young. As such, the birth might have occurred on one of the nights when MJ6 did not exit the den (i.e. 8, 9, 13 or 17 September). Finally, the fact that the young animal was able to move independently on 1 October (as recorded by the camera trap) suggests that it was a few weeks old then. Unfortunately, the gestation period cannot be determined in this study; Payne \& Francis (1998) speculated this to be fairly short at 2 to $3 \mathrm{mo}$, but they did not provide the basis for this time period.

Based on the first image of the young pangolin on 1 October, its total length was estimated to be around 30 to $35 \mathrm{~cm}$. Although there has not been any published data on the body measurements of Manis javanica neonates, the estimated body length compares well with the data on other pangolin species (Table 3). On 3 November, the young pangolin was observed to be slightly longer than the tail length of MJ6 (i.e. $43 \mathrm{~cm}_{\text {; }}$ Fig. 2). This observation lends support to Prater's (1965) example, where a baby pangolin doubled its mass in $4 \mathrm{mo}$, and to his view that growth in young pangolins is rapid. In addition, from this study and the limited reported dates of birth of the other pangolin species (Table 3), it seems that pangolins in general may reproduce all year round.

Unfortunately, due to the much-reduced range of the transmitter after 3 November, attempts to locate MJ6 for observations of maternal behaviour were mostly unsuccessful. Nevertheless, the observations on 5 January 2006 most likely signify that maternal care by MJ6 had ended by then. This is supported by the increasing number of events triggered by the young pangolin throughout the period, which clearly demonstrate its increased activity and ability to move around independently by mid-December. This may be indirect evidence for the readiness of the young pangolin to be independent. As a result, this suggests that the entire duration of maternal

Table 2. Manis javanica. Comparison of body measurements of MJ6 with other similar-sized female pangolins from Pulau Tekong

\begin{tabular}{|lccc|}
\hline Pangolin ID & $\begin{array}{c}\text { Head-body } \\
\text { length }(\mathrm{cm})\end{array}$ & $\begin{array}{c}\text { Tail length } \\
(\mathrm{cm})\end{array}$ & $\begin{array}{c}\text { Mass } \\
(\mathrm{kg})\end{array}$ \\
\hline MJ6 & 43 & 43 & 6.1 \\
MJ7 & 43 & 38 & 4.7 \\
MJ18 & 40 & 41 & 3.0 \\
MJ21 & 45 & 43 & 4.5 \\
\hline
\end{tabular}


Table 3. Manis spp. Reported date of birth (range is given where date is unknown) and body measurements of neonate pangolins. Data are for length and weight at birth where not otherwise stated. (-): data not reported

\begin{tabular}{|lccl|}
\hline Pangolin species & Date of birth & Length and mass & Source \\
\hline Manis crassicaudata & 6 Jan & $0.435 \mathrm{~m}$ at $3 \mathrm{~d}$ & Ogilvie \& Bridgewater (1967) \\
& ? Jul & - & Prater (1965) \\
& 17 Nov & $0.3 \mathrm{~m}, 235 \mathrm{~g}$ & Acharjyo \& Misra (1972) \\
& ? Nov & - & Asdell (1946) \\
& Jan-Mar & - & Asdell (1946), Prater (1965) \\
Manis pentadactyla & $5 \mathrm{Feb}$ & $0.2 \mathrm{~m}, 92 \mathrm{~g}$ & Heath \& Vanderlip (1988) \\
& ? Aug & - & Ogilvie \& Bridgewater (1967) \\
& 14 Nov & $0.21 \mathrm{~m}, 93 \mathrm{~g}$ & Heath \& Vanderlip (1988) \\
& 25 Dec & $200 \mathrm{~g}$ at $16 \mathrm{~d}$ & Masui (1967) \\
Nov-Feb & - & Fang \& Wang (1980), Fang (1981) \\
& 3 Nov & $100 \mathrm{~g}$ & Menzies (1967) \\
\hline
\end{tabular}

care was approximately 3 to 4 mo (mid-September till mid-December/early January) and is in accordance with the speculation of approximately 3 mo noted by Payne \& Francis (1998). On the other hand, a captive female Chinese pangolin Manis pentadactyla at Taipei Zoo is reported to have exhibited maternal care for as long as 6 mo (S. F. Chen, pers. comm.)

The data from the camera traps support the widely held notion that pangolins are mainly nocturnal in their activity (Payne \& Francis 1998, Parr 2003): MJ6 was found to be mainly nocturnal in habits and have a peak activity period between 03:00 and 06:00 h (Fig. 4).

The shift in activity towards the daylight hours took place in December during the final periods of den usage and coincided with an increase in activity recorded from MJ6 together with her young. Prior to December, complete activity records from the camera raps (i.e. when both exit and entry were recorded) always showed MJ6 alone, with the exception of relocation with her young to other natal dens. This suggests that the diurnal activity of MJ6 together with her young could signify the last phase of maternal care before the young became independent.

Throughout our observations, MJ6 was noticed to be utilizing dens that offered good concealment and also shelter from the elements. This is in contrast to tagged adult male pangolins, which often rest amongst clumps of Imperata cylindrica grasses or on branches of tall trees (N. T. L. Lim unpubl. data). Another way in which MJ6 behavior differed from that of adult male pangolins is the use of the dens for an extended period of time before moving to the next den. While repeated use of sleeping sites was also observed for adult tagged males, the sites were only used for a consecutive period of 1 or $2 \mathrm{~d}$ (N. T. L. Lim pers. obs.). This clearly demonstrates that the female pangolin MJ6 had a high level of den fidelity for extended periods during its reproductive stages. Unfortunately, it was not possible to observe den usage after the reproductive stages because of the severed antenna.

The recorded home range of the female MJ6 was only 10 to $24 \%$ of the home ranges of adult males observed by N.T.L.L. (unpubl. data). While radiotracking of MJ6 was limited in view of the pangolin's cautious behavior during the reproductive stages, we feel that this is unlikely to severely underestimate its home range. This is because $78 \%$ of the activity ( 7 out of 9 fixes) recorded throughout the entire period are within the boundaries of the 3 dens (Fig. 8) and the remaining 2 fixes were only about $35 \mathrm{~m}$ away from the outer boundaries set by the 3 dens. Furthermore, knowing that pangolins forage at a slow speed and MJ6 was only active for about $2 \mathrm{~h}$ each night, it is unlikely that its actual home range would differ greatly from the estimated values. Therefore, the vast difference between the home-range size of MJ6 and other adult males could be due to a limited number of suitable natal dens and also a result of reduced mobility during the reproductive stages (i.e. returning to the same den for extended periods instead of moving with her young to other dens on a regular basis).

Heath \& Coulson (1997a) reported that at least $85 \mathrm{~d}$ were required to achieve $90 \%$ of the home-range estimate for Manis temminckii at $180 \mathrm{~d}$. However, due to the limited radiotracking and the lack of a proper regime of data collection, we were not able to ascertain the duration of radiotracking required to give a reliable home-range estimate for MJ6.

With a potentially low rate of fecundity (i.e. 1 offspring per birth and a moderate period of maternal care), pangolins are prone to effects of over-harvesting. In fact, of the 4 Asiatic pangolins, the Sunda pangolin appears to be the species most threatened by trade (Bräutigam et al. 1994). Within the natural range of Manis javanica in southeast Asia, seizures of illegal shipments of the species with numbers of up to 1200 in 
one single load occur regularly (e.g. Abas 2002, Simon 2004). This is made worse by the fact that pangolins do not survive well in captivity (Wilson 1994), making animal rescue and rehabilitation before release back into the wild an arduous task.

The strict use of hollows of big trees $(>50 \mathrm{~cm} \mathrm{DBH})$ as natal dens by the female MJ6 suggests that Manis javanica might require reasonably mature forest to locate and utilize suitable den sites during reproductive stages. However, with the present rate of habitat degradation in Southeast Asia, the decrease in mature forests might reduce the number of suitable natal dens, and this will prove to be a limitation for the population sustainability.

In conclusion, it must be reiterated that this study is only based on the observations of a single female Manis javanica. As such, it is highly recommended that further long-term field studies be carried out on the elusive Sunda pangolin; this is increasingly urgent in view of the pressure from both illegal trade and habitat destruction or conversion.

Acknowledgements. This study is supported by Singapore Zoological Gardens and Wildlife Conservation Society, with kind permission from the Ministry of Defence and National Parks Board (research permit NP/RP453). We are most grateful to them and the many others who assisted in the field work, in particularly Alan W. M. Yeo, Kwok Wai Chan and Suay Hwee Yeo. We also thank Antony Lynam and Jeff La Valette for the assistance with the camera traps, Shiang-Fan Chen and Shin-Chien Chin for information on the captive Manis pentadactyla, and Ping Ting Chew for help with the figures. Comments from Kelvin K. P. Lim and 2 anonymous reviewers greatly improved the quality of the manuscript.

\section{LITERATURE CITED}

Abas A (2002) 1,200 frozen pangolins seized at Westport. New Straits Times, Malaysia, 20 Apr 2002

Acharjyo LN, Misra R (1972) Birth of an Indian pangolin (Manis crassicaudata) in captivity. J Bombay Nat Hist Soc 69:174-175

Asdell SA (1946) Patterns of mammalian reproduction. Comstock Publishing, Ithaca, NY

Bräutigam A, Howes J, Humphreys T, Hutton J (1994) Recent information on the status and utilization of African pangolins. TRAFFIC Bull 15:15-22

Chou LM, Tan HTW, Yeo DCJ (2006) The natural heritage of Singapore. Prentice Hall, Singapore

Fang LX (1981) Investigation on pangolins by following their trace and observing their cave. Nature (Beijing Natural History Museum) 3:64-66 (in Chinese)

Fang LX, Wang S (1980) A preliminary survey on the habits of pangolin. Mem Beijing Nat Hist Mus 7:1-6 (in Chinese)

Gaubert P, Antunes A (2005) Assessing the taxonomic status

Editorial responsibility: Alan Dixson,

Wellington, New Zealand of the Palawan pangolin Manis culionensis (Pholidota) using discrete morphological characters. J Mammal 86: 1068-1074

Heath ME, Coulson IM (1997a) Home range size and distribution in a wild population of Cape pangolins, Manis temminckii, in north-west Zimbabwe. Afr J Ecol 35:94-109

Heath ME, Coulson IM (1997b) Preliminary studies on relocation of Cape pangolins Manis temminckii. S Afr J Wildl Res 27:51-56

Heath ME, Coulson IM (1998) Measurements of length and mass in a wild population of Cape pangolins (Manis temminckii) in north-west Zimbabwe. Afr J Ecol 36:267-270

Heath ME, Vanderlip SL (1988) Biology, husbandry, and veterinary care of captive Chinese Pangolins (Manis pentadactyla). Zoo Biol 7:293-312

Inskipp T, Gillett HJ (eds) (2005) Checklist of CITES species and annotated CITES Appendices and reservations. CITES Secretariat and UNEP-WCMC, Geneva and Cambridge

IUCN (2006) 2006 IUCN Red List of Threatened Species. Available at: www.redlist.org

Lawson EJG, Rodgers AR (1997) Differences in home-range size computed in commonly used software programs. Wildl Soc Bull 25:721-729

Lekagul B, McNeely JA (1988) Mammals of Thailand. Association for the Conservation of Wildlife, Bangkok

Masui M (1967) Birth of a Chinese pangolin Manis pentadactyla at Ueno Zoo, Tokyo. Int Zoo Yearb 7:114-115

Menzies JI (1967) A preliminary note on the birth and development of a small-scaled tree pangolin Manis tricuspis at lfe University Zoo. Int Zoo Yearb 7:114

Mohr CO (1947) Table of equivalent populations of North American mammals. Am Midl Nat 37:223-249

Ogilvie PW, Bridgewater DD (1967) Notes on the breeding of an Indian pangolin (Manis crassicaudata) at Oklahoma Zoo. Int Zoo Yearb 7:116-118

Pagés E (1975) Etude éco-éthologique de Manis tricuspis par radio-tracking. Mammalia 39:613-641

Parr JWK (2003) A guide to the large mammals of Thailand. Sarakadee Press, Bangkok

Payne J, Francis CM (1998) A field guide to the mammals of Borneo. The Sabah Society, Kota Kinabalu

Prater SH (1965) The book of Indian animals. Bombay Natural History Society, Bombay

Richer RA, Coulson IM, Heath ME (1997) Foraging behaviour and ecology of the Cape pangolin (Manis temminckii) in north-western Zimbabwe. Afr Ecol 35:361-369

Shi YQ (1985) Feeding habits on Chinese pangolin (Manis pentadactyla). Chin Wildl 6:11-13 (in Chinese)

Simon A (2004) 800 pangolins found at factory. New Straits Times, Malaysia, 28 Sep 2004

South AB, Kenward RE, Walls SS (2005) Ranges 7 v 1.0: For the analysis of tracking and location data. Anatrack, Wareham

White GC, Garrot RA (1990) Analysis of radio-tracking data. Academic Press, New York

Wilson AE (1994) Husbandry of pangolins. Int Zoo Yearb 33: 248-251

Wu SB, Liu NF, Ma GZ, Xu ZR, Chen H (2003) Habitat selection by Chinese pangolin (Manis pentadactyla) in winter in Dawuling Natural Reserve. Mammalia 67:493-501

Submitted: December 15, 2006; Accepted: March 7, 2007

Proofs received from author(s): June 15, 2007 